\title{
PERANCANGAN APLIKASI SURAT MASUK DAN SURAT KELUAR BERBASIS JAVA DI PT AFCONSULT ENERGY INDONESIA
}

\author{
Hermansyah $^{1}$, Een Juhriah ${ }^{2}$, Maria Adelina Saragih ${ }^{3}$ \\ Program Studi Teknik Informatika, Fakultas Teknik dan Ilmu Komputer, \\ Universitas Indraprasta PGRI \\ Jalan Raya Tengah No 80, Kelurahan Gedong, Pasar Rebo, Jakarta Timur \\ hermansyah2481@yahoo.co.id ${ }^{1}$, eenunindra@gmail.com², adelinasaragih@gmail.com³
}

\begin{abstract}
Abstrak
Sistem surat menyurat adalah sebuah kegiatan yang penting dalam suatu perusahaan, maka harus diatur secara efektif dan juga efisien. Tujuan dari penelitian ini adalah untuk menganalisa sistem yang sedang berjalan di P. Afconsult Energy Indonesia. Metode penelitian yang digunakan adalah grounded research untuk mendeskripsikan sistem yang berjalan dan perancangan yang akan dibuat. Metode analisis dilakukan dengan melakukan observasi langsung di perusahaan, dokumentasi dan mempelajari dokumen-dokumen yang tersedia, dan wawancara kepada pihak terkait di perusahaan. Metode kepustakaan dilakukan dengan mencari data-data dan informasi-informasi tambahan dari berbagai buku. Peneliti mendapat hasil penelitian bahwa sistem pengarsipan surat ini sangat bermanfaat bagi perusahaan. Adapun manfaat dari sistem ini adalah sangat membantu para karyawan dalam pengolahan surat di dalam perusahaan tersebut, meudahkan dalam pencarian data yang diperlukan, dan tersedianya laporan yang tepat dan akurat saat dibutuhkan. Kesimpulan dari penelitian ini adalah dengan diterapkannya aplikasi surat masuk dan surat keluar ini dapat memudahkan dan mempercepat sistem pengolahan surat pada perusahaan, menjadi lebih baik dan lebih efisien.
\end{abstract}

Kata Kunci: Surat, Perancangan, Sistem.

\begin{abstract}
Correspondence system is an important activity in a company, it must be regulated effectively and also efficiently. The purpose of this research is to analyze the current system in PTAfconsult Energy Indonesia. The research method used is grounded research to describe the running system and the design to be made. The analysis method is carried out by conducting direct observation in the company, documentation and studying the available documents, and interviews to related parties in the company. The library method is done by searching for additional data and information from various books. Researchers got the results of research that the letter archiving system is very beneficial for the company. The benefits of this system are very helpful for employees in processing letters within the company, in the search for the necessary data, and the availability of accurate and accurate reports when needed. The conclusion of this research is by applying the application of incoming and outgoing mail can facilitate and accelerate the processing system of letters in the company, to be better and more efficient.
\end{abstract}

Keywords: Letter, Design, System.

\section{PENDAHULUAN}

Pada masa ini perkembangan teknologi dan komputer bertambah pesat terutama dalam bidang komputer. Berbagai kegiatan untuk mendapatkan informasi menjadi lebih mudah dan lebih cepat dilakukan, dibidang bisnis memiliki kaitan erat dengan teknologi informasi untuk itu maka dapat mempermudah dan memajukan perusahaan tersebut agar terus berkembang.

Sistem yang digunakan untuk mencatat surat masuk dan surat keluar pada PT Afconsult Energy Indonesia saat ini masih dilakukan secara manual atau ditulis langsung di dalam buku atau catatan.

Didalam perusahaan penggunaan komputer bukanlah merupakan hal yang baru karena komputer dapat menjadi sebagai alat bantu untuk melakukan aktifitas dan segala tugas pekerjaan, pengolahan data dan menyimpanan data dimana dihasilkan suatu informasi yang cepat, tepat dan akurat.

Dalam metode pencatatan surat masuk dan surat keluar sebagai contoh yang sangat penting di dalam suatu perusahaan untuk mengetahui berbagai informasi yang masuk dan keluar. Maka dari 
itu penerapan teknologi dalam bidang tersebut sangat dibutuhkan untuk mendapatkan segala informasi dengan cepat dan mudah.

Maka dari itu ketika ada informasi atau data yang dibutuhkan secara cepat dan mendadak sangat sulit untuk didapat. Maka dari setiap masalah yang sering muncul dan terjadi tersebut peneliti melakukan penelitian dan mencoba mengatasi masalah yang sering timbul dalam sistem surat masuk dan surat keluar pada PT Afconsult Energy Indonesia. Studi tentang tata kelola surat pernah dilakukan oleh beberapa peneliti sebelumnya, (Rahayu \& Hana, n.d.) dengan "sistem informasi pendataan surat masuk dan surat keluar pada SMK Negeri 5 Tanggerang", (Supriadi et al., 2018) dengan "Rancang bangun aplikasi surat masuk dan surat keluar berbasis web pada kantor asuransi jiwa kantor layanan" dan (Rahmah, 2014) dengan "Perancangan aplikasi sistem persuratan berbasis web pada PT Dwi pilar pratama".

\section{PENELITIAN RELEVAN}

Dalam melakukan penelitian tentang sistem surat masuk dan surat keluar di PT Afconsult Energy Indonesia, peneliti menggunakan bahan referensi dari berbagai sumber, antara lain dari penelitian mahasiswa Universitas Indraprasta angkatan terdahulu yang ada pada perpustakaan, dari jurnal mahasiswa yang ada di internet, serta beberapa buku yang menunjang untuk data-data yang dibutuhkan.Contohnya buku dari (Raharjo, 2018) berjudul "Pemrograman C++ Revisi Kedua" dan (Nofriadi, 2015) berjudul "Java Fudamental dengan Netbeans 8.0.2".

Penelitian yang relevan yang dilakukan (Ferdinandus et al., n.d.) yang berjudul "Perancangan Aplikasi Surat Masuk Dan Surat Keluar Pada PT . PLN ( Persero ) Wilayah Suluttenggo". Hasil penelitian tersebut adalah aplikasi penyimpanan data-data memo yang masuk dan keluar yang diharapkan dapat membantu kinerja karyawan. Penelitian selanjutnya dilakukan (Vironica, 2013) yang berjudul "Rancang Bangun Aplikasi Pengelolaan Surat Masuk dan Surat Keluar Pada Sekolah Menengah Pertama Negri 2 Nawangan". Hasil penelitian tersebut adalah aplikasi surat masuk dan surat keluar yang menggunakan database mysql yang dapat memudahkan pengarsipan surat di sekolah tersebut.

\section{METODE PENELITIAN \\ Teknik Pengumpulan Data}

Metode penelitian yang digunakan adalah metode grounded (grounded research) yaitu suatu metode penelitian berdasarkan pada fakta dan menggunakan analisis perbandingan dengan tujuan mengadakan generalisasi empiris, menetapkan konsep, membuktikan teori, mengembangkan teori, pengumpulan dan analisis data dalam waktu yang bersamaan. Setelah mengumpulkan data, peneliti melanjutkan proses penelitian sesuai dengan langkah-langkah pokok yang digunakan pada metode ini. Metode pengumpulan data yang dilakukan oleh peneliti untuk mendapatkan data-data serta informasi untuk mendukung penyempurnaan hasil dari penelitian ini antara lain :

\section{a. Studi kepustakaan}

Pengumpulan data dan informasi dari kutipan buku-buku, artikel-artikel, hasil laporan, serta bahan lainnya yang berkaitan dengan penelitian ini. Dari bahan-bahan tersebut diambil teoriteori yang dapat dijadikan landasan untuk menganalisis masalah yang ditemukan dalam penelitian dan digunakan untuk menyelesaikan maslah tersebut. Contohnya adalah (Supriyati et al., n.d.) yang berjudul "Aplikasi pendataan surat masuk dan surat keluar pada erusahaan ABC di wilayah Lampung", (Sugiharti \& Triliani, 2014) berjudul "Perancangan Aplikasi Surat Masuk dan Keluar pada PT . Angkasa Pura 1 Semarang" dan (Darlianto et al., 2016) berjudul "Sistem informasi pencatatan surat masuk ( Studi Kasus : Kantor Camat Kampar Kiri Kabupaten Kampar Provinsi Riau )".

\section{b. Studi lapangan}

Studi lapangan dilakukan dengan melihat langsung penanganan surat masuk dan surat keluar PT Afconsult Energy Indonesia. Dalam studi lapangan ini dipergunakan teknik pengumpulan data antara lain dengan cara peneliti melakukan survei atau observasi untuk mengamati secara langsung bagaimana proses penanganan surat masuk dan surat keluar. 


\section{c. Wawancara}

Data dan informasi yang diperoleh untuk mendukung penelitian ini diambil dari sumber data primer yang diperoleh langsung melalui sumber data sekunder yang merupakan data pendukung untuk melengkapi data primer yang diperoleh melalui tanya jawab langsung dengan ibu Ajeng Siti Chodijah selaku Representative dari PT Afconsult Energy Indonesia.

\section{Langkah-langkah Pengembangan Sistem}

a. Analisa Kebutuhan

Analisa kebutuhan berguna untuk mendapatkan data dan informasi yang akan digunakan sebagai masukan dari suatu sistem dan untuk memperoleh data yang berhubungan dengan penelitian ini.

b. Studi Kepustakaan

Studi kepustakaan bertujuan untuk mengetahui, mempelajari dan memahami dasar teori yang berhubungan dengan analisa kebutuhan yang telah dilakukan.

c. Perancangan Sistem

Perancangan sistem bertujuan untuk merancang sistem yang akan dibuat agar dapat diimplementasikan sesuai dengan kebutuhan pengguna.

d. Pengujian

Pengujian adalah proses menguji aplikasi yang telah dibuat. Tahap ini bertujuan untuk memastikan semua fungsi aplikasi bekerja dengan baik, sesuai dengan kebutuhan dan mencari apakah masih ada kesalahan pada aplikasi.

e. Implementasi aplikasi dan evaluasi aplikasi

Implementasi adalah proses mengartikan dokumen hasil desain menjadi baris-baris perintah bahasa pemrograman komputer. Semakin baik hasil analisis dan desain yang dilakukan, maka proses pengkodean ini akan lebih mudah dilakukan.

\section{HASIL DAN PEMBAHASAN}

\section{Analisis Permasalahan}

Dari hasil yang peneliti lakukan maka peneliti dapat menganalisis permasalahan yang ada pada sistem pengarsipan surat masuk dan surat keluar di PT Afconsult Energy Indonesia, yaitu :

1. Dalam proses pencatatan surat masuk dan surat keluar sering terjadi keterlambatan dan kesalahan dalam pencatatannya dan dalam proses pembuatan laporan surat masuk dan surat keluar karena masih dilakukan secara manual.

2. Dalam proses pencarian data arsip yang diperlukan sering terjadinya data ganda dan waktu yang diperlukan juga terlalu lama.

3. Pendistribusian surat dilaksanakan secara manual sehingga memperlambat kerja pencatatan.

\section{Alternatif Penyelesaian Masalah}

Alternatif penyelesaian masalah yang akan peneliti lakukan untuk mempermudah proses kerja pada PT Afconsult Energy Indonesia, yaitu :

1. Membuat sistem penginputan data berbasis komputer atau java. Sehingga data tidak akan mengalami kehilangan dan pencatatan data secara berulang-ulang.

2. Pembuatan perancangan penginputan data surat masuk dan surat keluar yang lebih efektif dan dinamis berbasis java.

3. Laporan surat dibuat sebaik dan efisien mungkin agar mudah didapat dan dimengerti oleh semua orang dan tidak membutuhkan waktu yang lama. 


\section{Diagram Alir Data (DAD) Sistem Yang Diusulkan}

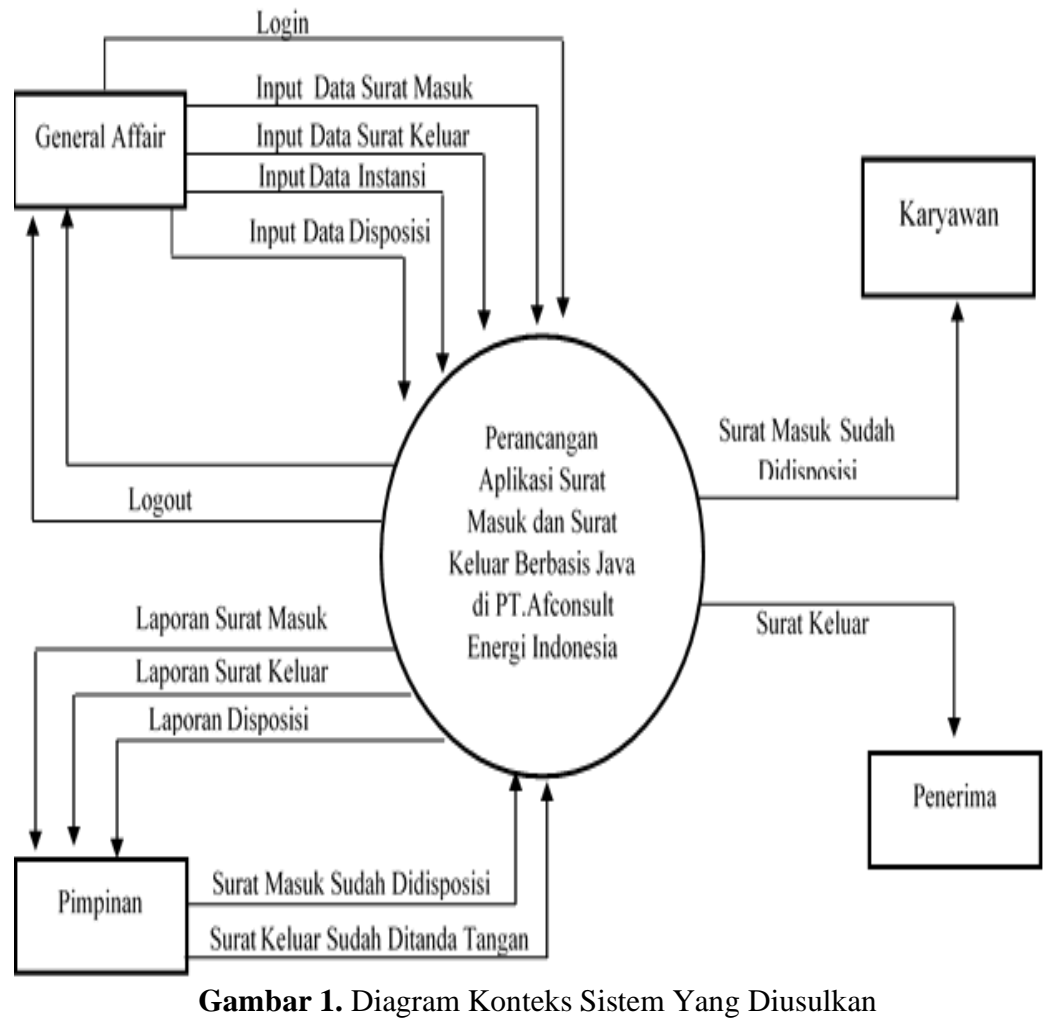

\section{Normalisasi Tahap Kedua (2NF)}

\begin{tabular}{|c|}
\hline No_surat * \\
\cline { 2 - 2 } Tgl_Terima \\
Tgl_Surat \\
Instansi ** \\
Prihal \\
Lampiran \\
Disposisi \\
Tujuan \\
\hline
\end{tabular}

$\longrightarrow$

No_surat *
Tgl_Surat
Instansi **
Prihal
Keterangan
Lampiran
Tujuan

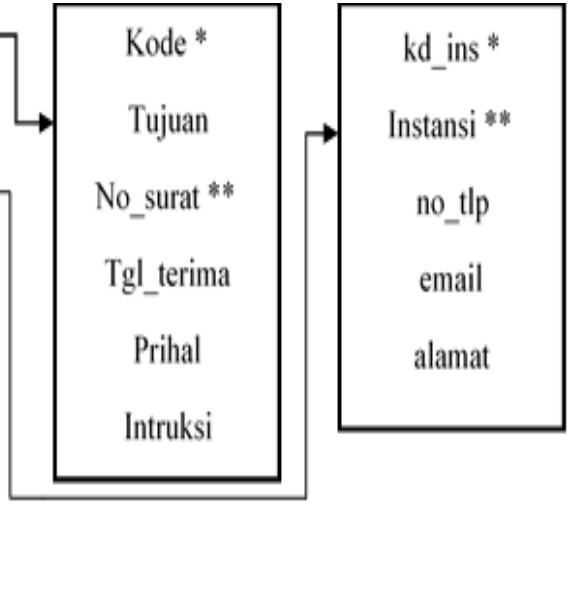

Gambar 2. Normalisasi Tahap Kedua (2NF)

Perancangan Aplikasi Surat Masuk dan Surat Keluar Berbasis Java di PT Afconsult Energy Indonesia

Perancangan Aplikasi Surat Masuk dan Surat Keluar Berbasis Java di PT Afconsult Energy Indonesia di buat dengan menggunakan bahasa pemrograman java. Sedangkan java merupakan bahasa pemrograman yang portable karena dapat dijalankan di banyak sistem operasi saat ini. 


\section{Tampilan Login}

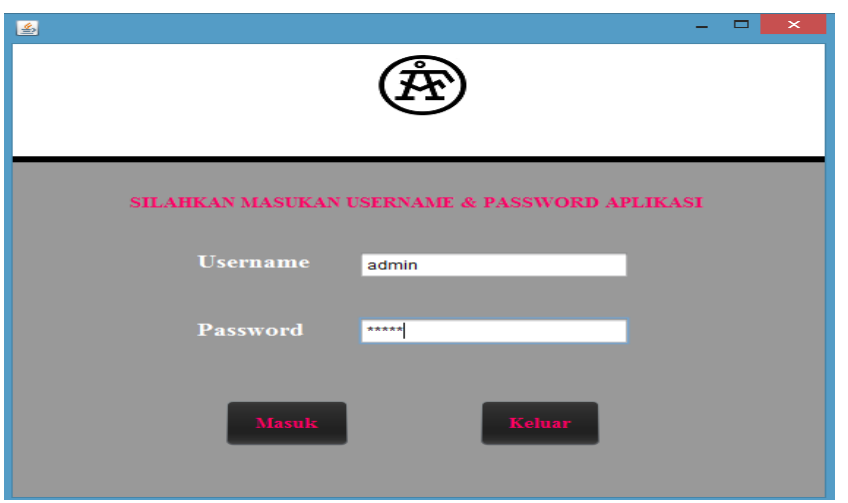

Gambar 3. Tampilan Login

Pada saat program pertama kali dijalankan maka tampilan yang akan muncul adalah form login, yang mengharuskan pengguna untuk memasukkan nama user beserta password bawaan program tersebut.

\section{Tampilan Menu Utama}

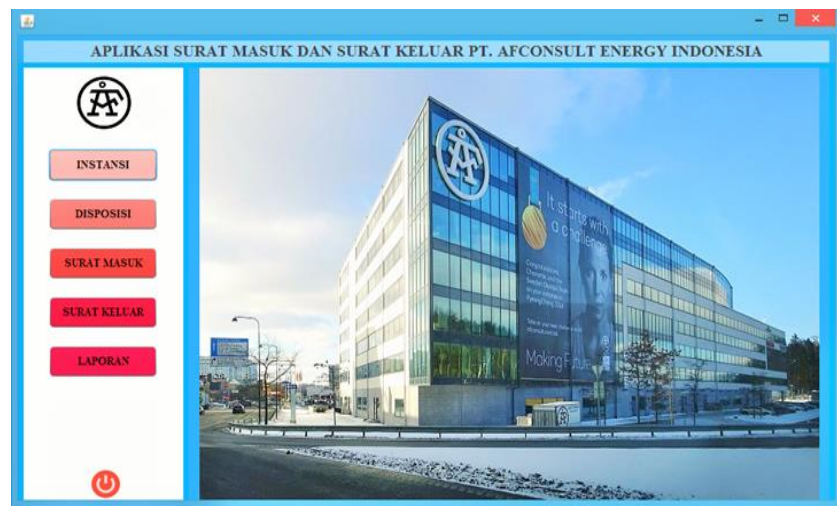

Gambar 4. Tampilan Menu Utama

Setelah masuk ke dalam program akan muncul tampilan menu utama, pengguna dapat memilih menu yang tersedia pada tampilan seperti input data instansi, input disposisi, input surat masuk, input surat keluar, cetak laporan dan logo shutdown berfungsi kembali ke tampilan login.

\section{Tampilan Input Data Instansi}

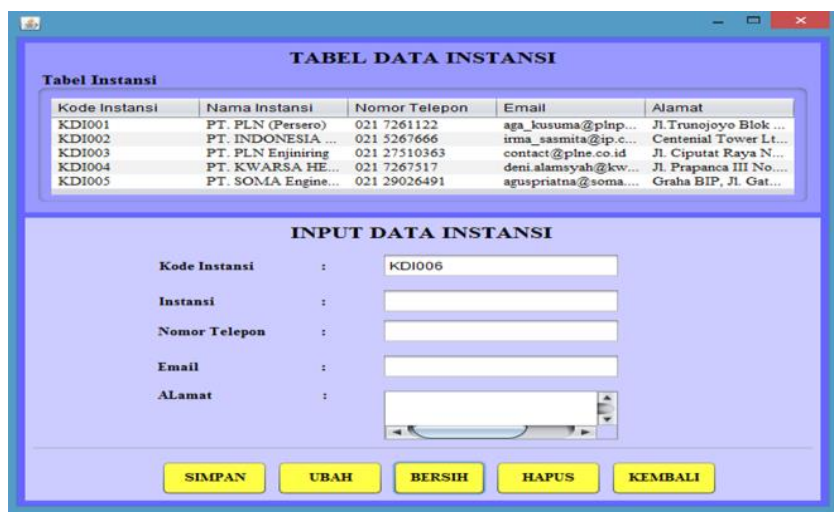

Gambar 5. Tampilan Input Data Instansi

Tampilan ini merupakan tampilan untuk input data instansi yang ada pada aplikasi surat masuk dan surat keluar di PT Afconsult Energy Indonesia. 


\section{Tampilan Input Disposisi}

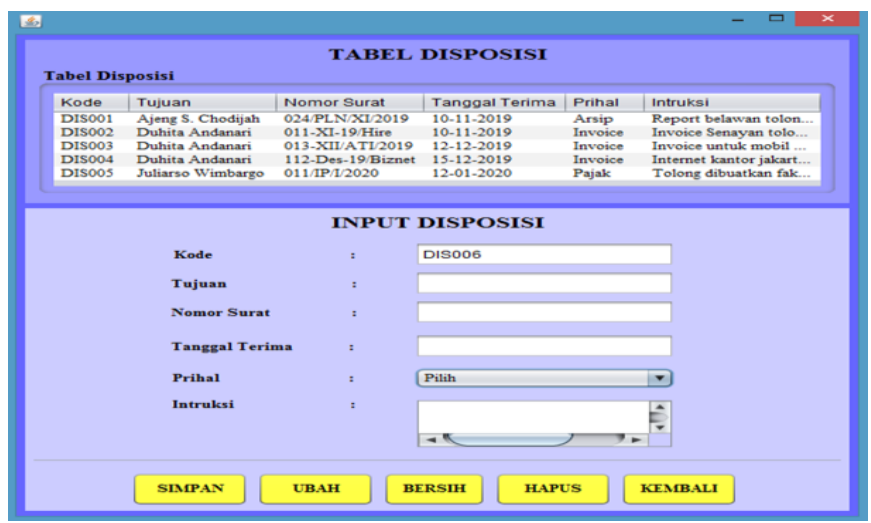

Gambar 6. Tampilan Input Disposisi

Tampilan ini merupakan tampilan untuk input data disposisi yang ada pada aplikasi surat masuk dan surat keluar di PT Afconsult Energy Indonesia.

\section{Tampilan Input Surat Masuk}

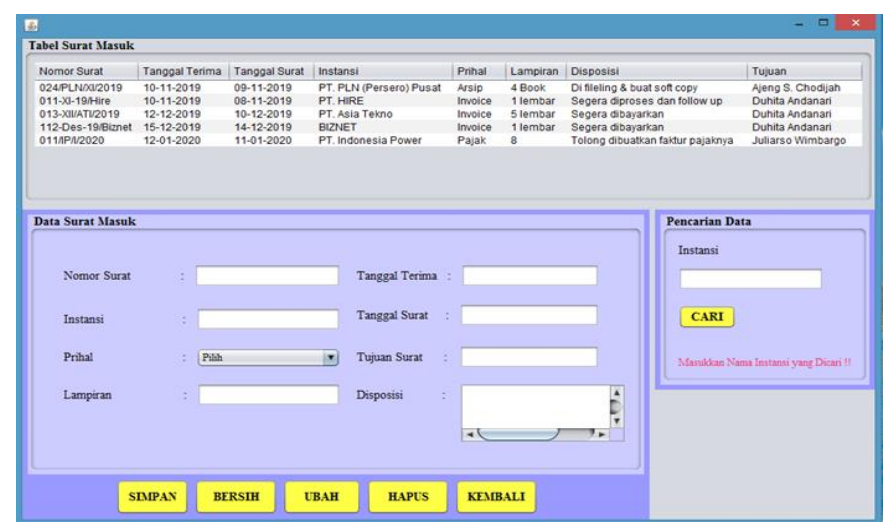

Gambar 7. Tampilan Input Surat Masuk

Tampilan ini merupakan tampilan untuk input data surat masuk yang ada pada aplikasi surat masuk dan surat keluar di PT Afconsult Energy Indonesia.

\section{Tampilan Input Surat Keluar}

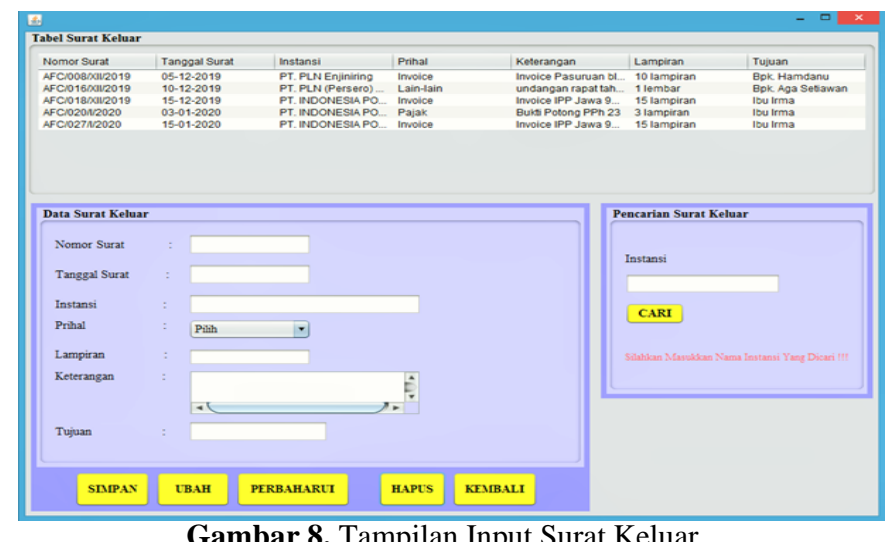

Tampilan ini merupakan tampilan untuk input data surat keluar yang ada pada aplikasi surat masuk dan surat keluar di PT Afconsult Energy Indonesia. 


\section{Tampilan Laporan Data Instansi}

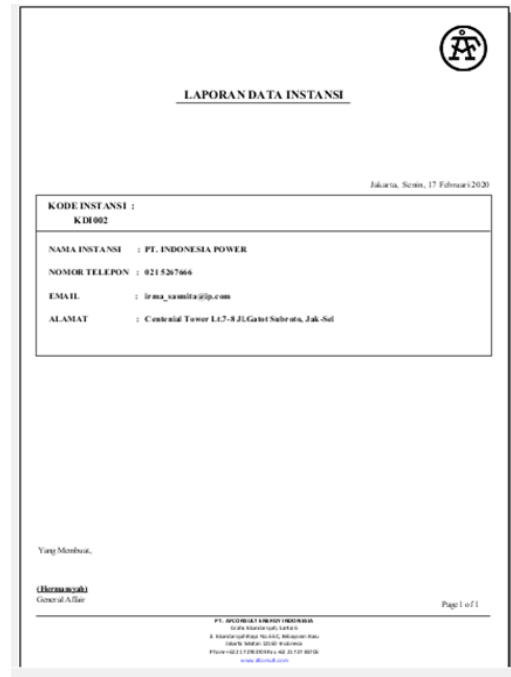

Gambar 9. Tampilan Laporan Data Instansi

Tampilan ini merupakan tampilan bentuk laporan data instansi yang berhasil dicetak pada aplikasi surat masuk dan surat keluar di PT Afconsult Energy Indonesia.

\section{Tampilan Laporan Disposisi}

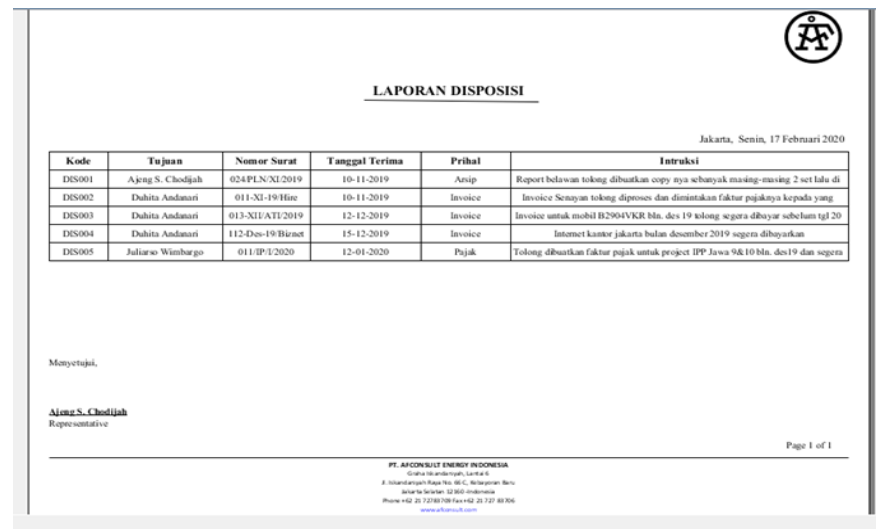

Gambar 10. Tampilan Laporan Disposisi

Tampilan ini merupakan tampilan bentuk laporan disposisi yang berhasil dicetak pada aplikasi surat masuk dan surat keluar di PT Afconsult Energy Indonesia.

\section{Tampilan Laporan Surat Masuk}

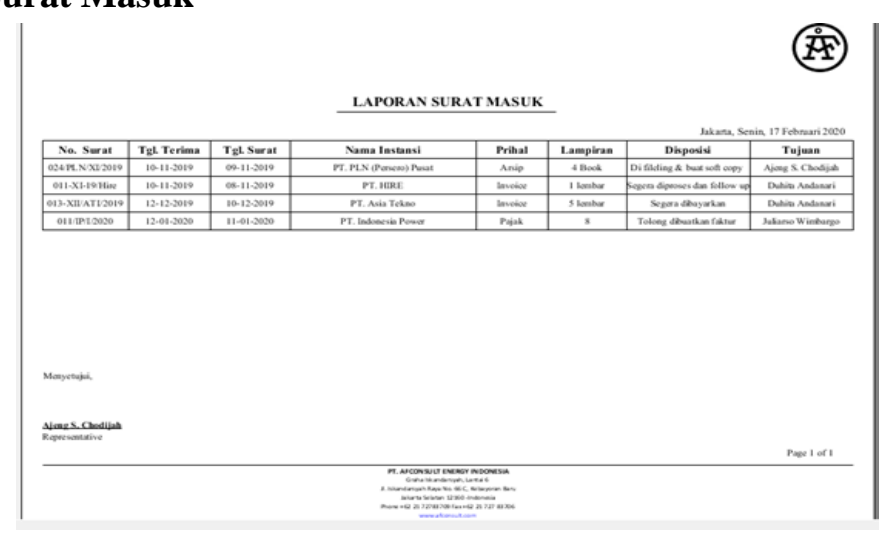

Gambar 11. Tampilan Laporan Surat Masuk

Tampilan ini merupakan tampilan bentuk laporan surat masuk yang berhasil dicetak pada aplikasi surat masuk dan surat keluar di PT Afconsult Energy Indonesia. 


\section{Tampilan Laporan Surat Keluar}

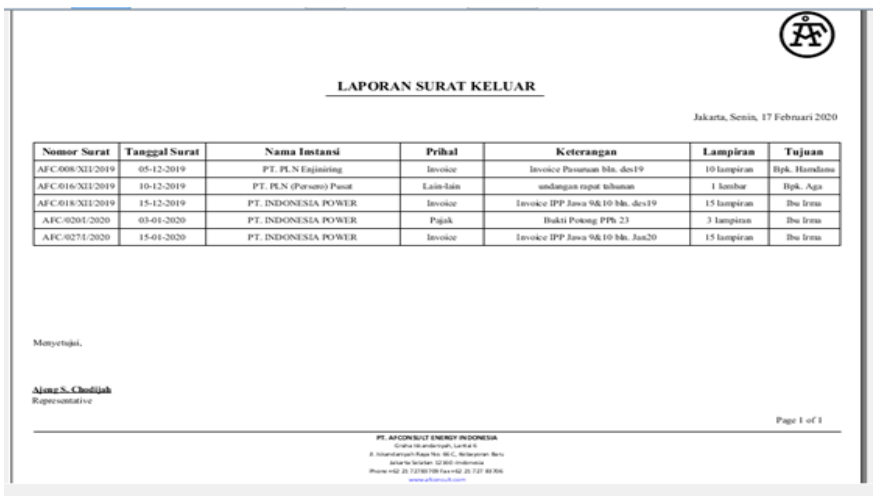

Gambar 12. Tampilan Laporan Surat Keluar

Tampilan ini merupakan tampilan bentuk laporan surat keluar yang berhasil dicetak pada aplikasi surat masuk dan surat keluar di PT Afconsult Energy Indonesia.

\section{SIMPULAN}

Berdasarkan hasil dari penelitian, maka dapat disimpulkan bahwa aplikasi surat masuk dan surat keluar ini dibuat atas dasar keterbatasan dalam pengolahan surat masuk dan surat keluar yang dilakukan pada PT Afconsult Energy Indonesia, sehingga peneliti bermaksud untuk memberikan inovasi dalam proses pengolahan surat masuk dan surat keluar di perusahaan tersebut dan berharap agar sistem yang peneliti usulkan tersebut dapat mempermudah dan mempercepat jalannya proses pengarsipan surat di PT Afconsult Energy Indonesia.

Aplikasi surat masuk dan surat keluar berbasis java ini dibuat dengan sistem pengoperasian yang terkomputerisasi sehingga dapat lebih memudahkan pengguna atau karyawan yang bersangkutan nantinya dalam mengolah, menyimpan dan juga membuat laporan. Sistem penyimpanan yang menggunakan mysql diharapkan dapat menampung dan mengolah data lebih baik lagi dibandingkan dengan cara manual yang sebelumnya diterapkan di perusahaan tersebut.

Tampilan aplikasi yang dibuat sederhana diharapkan peneliti dapat mudah dipahami oleh pengguna nantinya dan dapat diterapkan dalam waktu yang cepat, sehingga tidak perlu terlalu lama untuk mempelajari dan menjalankan program tersebut.

\section{DAFTAR PUSTAKA}

Darlianto, A., Permana, I., Sistem, J., Fakultas, I., Uin, T., Riau, S., Hr, J., \& Km, S. (2016). SISTEM INFORMASI PENCATATAN SURAT MASUK (Studi Kasus : Kantor Camat Kampar Kiri Kabupaten Kampar Provinsi Riau). 2(1), 37-43.

Ferdinandus, S., Wowor, I. H., Kom, M., Lumenta, A. S. M., \& Rumagit, M. T. A. (n.d.). Perancangan Aplikasi Surat Masuk Dan Surat Keluar Pada PT . PLN ( Persero ) Wilayah Suluttenggo. 1-7.

Nofriadi. (2015). Java Fudamental dengan Netbeans 8.0.2. deepublish.

Raharjo, B. (2018). Pemrograman C++ Revisi Kedua. INFORMATIKA.

Rahayu, S., \& Hana, D. (n.d.). Sistem Informasi Pendataan Surat Masuk dan Surat Keluar Pada SMK Negeri 5 Tangerang. 138-147.

Rahmah, D. L. (2014). PERANCANGAN APLIKASI SISTEM PERSURATAN BERBASIS WEB PADA PT . DWI PILAR PRATAMA. 7(3), 282-292.

Sugiharti, E., \& Triliani, S. E. (2014). Perancangan Aplikasi Surat Masuk dan Keluar pada PT . Angkasa Pura 1 Semarang. 1(1).

Supriadi, I., Indrayani, R., \& Trysda, V. (2018). RANCANG BANGUN APLIKASI SURAT MASUK DAN SURAT KELUAR BERBASIS WEB PADA KANTOR ASURANSI JIWA KANTOR LAYANAN. 8-9.

Supriyati, D., Jaya, T. S., \& Yusman, M. (n.d.). Aplikasi Pendataan Surat Masuk dan Surat Keluar pada Perusahaan ABC di Wilayah Lampung. 1-6.

Vironica, A. (2013). Rancang Bangun Aplikasi Pengelolaan Surat Masuk Dan Surat Keluar Pada Sekolah Menengah Pertama Negeri 2 Nawangan. 5(4), 44-51. 